\title{
Revisión y actualización de la teología de los fundadores a partir de la crisis de los abusos
}

\author{
JuAn BaUtista DuHau \\ Centro de Estudios Filosóficos y Teológicos - Córdoba - Argentina \\ jbduhau@outlook.com.ar \\ (Dhttps:// orcid.org/0000-0001-9159-215X
}

Resumen: El escándalo de los abusos sexuales presenta consecuencias eclesiológicas para la Iglesia universal y local; y también para las organizaciones de la dimensión carismática, tanto antiguas como recientes. En este artículo se plantea una necesaria revisión y actualización de la reflexión teológica sobre los fundadores, a partir de las revelaciones sobre abusos de varios fundadores o líderes de nuevos movimientos y comunidades. Se discutirá la utilización de la reflexión realizada por las congregaciones tradicionales sobre sus fundadores en el posconcilio por parte de las nuevas comunidades para validar las figuras de sus iniciadores carismáticos.

Palabras clave: Fundador, vida consagrada, nuevas comunidades, nuevos movimientos eclesiales, escándalo, abusos sexuales.

Abstract: The sexual abuse scandal has ecclesiological consequences for the Roman Catholic Church at international and local levels, and also for ancient and modern organizations of the charismatic dimension. In this article we propose a vital review and update of the theological reflection on the founders from the revelations about abuses on the part of several founders or leaders of new movements and communities. We will discuss how the new communities use the interpretation made by traditional congregations on their founders in the postcouncil, to validate the figures of their charismatic initiators.

Keywords: Founders, consecrated life, new communities, new ecclesial movements, scandal, sexual abuse. 


\section{INTRODUCCIÓN}

La crisis producida por las continuas revelaciones de abusos sexuales es uno de los mayores desafíos que debe enfrentar la Iglesia en el presente y hacia el futuro. Resulta imprescindible asumir que los problemas desnudados por la crisis de abusos son un signo de los tiempos con los cuales hay que dialogar teológicamente ${ }^{1}$, acuñando visiones eclesiológicas que puedan ser un aporte a respuestas institucionales de remediación y reforma en la comunidad eclesial ${ }^{2}$.

De algún modo es necesario realizar una recepción del incipiente camino eclesial que se recorre en la elaboración de estas dramáticas cuestiones, reconociendo primero que no se trata de "temas", sino de víctimas que deben encontrar caminos de justicia y reparación, y de instituciones que deben transformarse para sanar, reparar y evitar la repetición de estas aberrantes conductas.

Teniendo en cuenta que la recepción "implica un aporte propio de consentimiento, de juicio en ocasiones, expresando así la vida de un cuerpo que pone en juego recursos espirituales originales"3; se busca reflexionar a partir de los hechos y su lectura teológica en un ámbito: las organizaciones carismáticas nacidas en derredor del Concilio Vaticano II y desarrolladas especialmente durante el pontificado de Juan Pablo II. Se busca dar un paso más para aceptar críticamente las revelaciones producidas en esta crisis y desde allí reflexionar teológicamente con el horizonte concreto de iluminar futuras opciones institucionales y pastorales.

Si hasta el momento los nuevos movimientos eclesiales, las nuevas comunidades y las nuevas formas de vida consagrada ${ }^{4}$ no han formado parte de la conversación sobre la crisis de los abusos, y se han mantenido en silencio sobre la cuestión inevitable de la reforma, conviene encontrar vías para que se

${ }^{1}$ Cf. M. FAggioli, "The Catholic Sexual Abuse Crisis as a Theological Crisis: Emerging Issues", Theological Studies 80 (2019) 573, en línea: https://doi.org/10.1177/00405639 19856610 (consulta: 01/07/2020).

2 Cf. C. SCHickendantz, "Fracaso institucional de un modelo teológico-cultural de Iglesia. Factores sistémicos en la crisis de los abusos", Teología y Vida 60/1 (2019) 12, en línea: https://doi.org/10.4067/S0049-34492019000100009 (consulta: 01/07/2020).

${ }^{3}$ Y. M.-J. CONGAR, "La recepción como realidad eclesiológica", Concilium 77 (1972) 58.

4 Se trata de una "galaxia" de organizaciones, asociaciones y grupos de lo más diversas que conforman el conglomerado de las "nuevas realidades eclesiales" y que optamos por denominar "nuevas organizaciones carismáticas". Cf. M. FAGGIOLI - D. S. YoCUM, Sorting Out Catholicism: A Brief History of the New Ecclesial Movements (Liturgical Press, 2014) 27. 211, en línea: http://muse.jhu.edu/book/46640 (consulta: 01/07/2020); J. B. DuHAU, "Carisma e institución en las nuevas realidades carismáticas. Crecimiento y crisis en los movimientos eclesiales y nuevas comunidades", Teología 55 (2019) 189-212, en línea: http://erevistas.uca. edu.ar/index.php/TEO/article/view/1673 (consulta: 01/07/2020). 
inicie esa reflexión. La posibilidad de entrar en diálogo sobre estas temáticas será un aporte para su futuro y su vitalidad en la Iglesia ${ }^{5}$.

Una de las contribuciones posibles es una revisión y actualización de la teología de los fundadores a partir de la crisis de los abusos en el seno de las organizaciones carismáticas nacidas alrededor del Concilio Vaticano II. Para ello se dará cuenta del surgimiento de la cuestión teológica de los fundadores, en relación a las organizaciones de la dimensión carismática de la Iglesia más antiguas y tradicionales, como las congregaciones masculinas y femeninas y los Institutos de Vida Apostólica.

En un segundo paso se abordará cómo y porqué estos desarrollos teológicos fueron asumidos por las nuevas organizaciones carismáticas -movimientos, nuevas comunidades, nuevas formas carismáticas- o por nuevas congregaciones e institutos. Luego se presentará un recorrido de las investigaciones recientes que permitan tomar real dimensión de la escala de la problemática planteada por los abusos, justificando así el valor de una reflexión teológica sobre el tema en el ámbito de las organizaciones carismáticas.

Finalmente, se pondrá en discusión si es posible que el primer desarrollo teológico sobre los fundadores, elaborado en los años previos a las revelaciones de los escándalos de los abusos, sea utilizado acríticamente para validar las figuras de fundadores de las nuevas realidades. Asimismo, se intentará identificar la evolución o la necesidad de desarrollo en los conceptos elaborados en la primera recepción del Concilio Vaticano II, atendiendo a las revelaciones producidas en este último tiempo sobre el ambiguo comportamiento de notable cantidad de personalidades carismáticas relevantes.

\section{LA REFLEXIÓN SOBRE LOS FUNDADORES EN EL CERCANO POSCONCILIO}

Si bien con Pío XI (1857-1939) se inicia la reflexión sobre el papel de los fundadores en el nacimiento de las familias religiosas, es recién con la recepción de los documentos del Concilio Vaticano II que se desarrolla una teología sobre los carismas y los fundadores. Los padres conciliares reconocen desde los orígenes de la Iglesia la existencia de hombres y mujeres ilustres que -de distintas y peculiares maneras- establecieron familias religiosas (cf. LG 45) y fijaron sus reglas y modus vivendi (cf. PC 1). El Vaticano II, invitando a la adecuada adaptación y renovación de la vida religiosa, propone reconocer la inspiración originaria, el espíritu y la índole genuina de cada familia religiosa (cf. PC 2.20) teniendo en cuenta que para ello es necesario conocer y conservar

\footnotetext{
${ }^{5}$ Cf. M. Faggioli, “The Catholic Sexual Abuse Crisis as a Theological Crisis: Emerging Issues", 586.
} 
“con fidelidad el espíritu y los propósitos de los fundadores, lo mismo que las sanas tradiciones, pues, todo ello constituye el patrimonio de cada uno de los institutos" (PC 2).

Como se puede ver, aún no se ha incorporado el término "carisma" en este campo semántico particular. Será Pablo VI quién primero utiliza la expresión "carisma de la vida religiosa" (charisma vitae religiosae) en la exhortación apostólica Evangelica testificatio (1971), indicando que "el carisma de la vida religiosa lejos de ser un impulso nacido «de la carne y de la sangre», u originado por una mentalidad que «se conforma al mundo presente», es el fruto del Espíritu Santo que actúa siempre en la Iglesia" (ET 11). Y durante su pontificado también el documento Mutuae relationes afirmará que existen en la Iglesia diversos institutos religiosos "cada uno con su propia índole; pero todos aportan su propia vocación, cual don hecho por el Espíritu, por medio de hombres y mujeres insignes y aprobado auténticamente por la sagrada jerarquía" (MR 11) ${ }^{6}$.

Contemporáneamente comienza también a utilizarse la expresión "carisma de los fundadores". Pablo VI empleará esta terminología al dirigirse a un capítulo de religiosos en el año 1969 y en la exhortación apostólica Evangelica testificatio ${ }^{7}$. Alli exhorta a los religiosos a despertar de nuevo los corazones a la verdad y al amor según el carisma de sus fundadores que Dios ha suscitado en su Iglesia, y recuerda que el Concilio insistió en la obligación de ser fieles al espíritu, a las intenciones evangélicas y al ejemplo de santidad de los fundadores (Cf. ET 11).

Con el desarrollo del neologismo "carisma", en la teología de la vida religiosa posconciliar, se sucede la acuñación de nuevos términos para referirse a los fundadores y a sus familias religiosas. Sintéticamente, se habla de "carisma de los fundadores" para indicar un don del Espíritu que capacita para alumbrar

\footnotetext{
${ }^{6}$ La vida consagrada se realiza habitualmente dentro de un instituto de vida consagrada, donde la profesión de los consejos evangélicos se inserta en un proyecto de vida evangélico según la variedad de los dones del Espíritu. Este proyecto de vida evangélico, originado en Dios, constituye un carisma, o en lenguaje canónico un patrimonio, que presenta características propias: su originalidad derivada del Espíritu, finalidad, índole y espiritualidad, estilo de vida, de apostolado y de santificación. Cf. V. DE PAOLIS, La vida consagrada en la Iglesia (BAC, Madrid 2011) 465. El CIC en lugar de carisma prefiere hablar de patrimonio y lo define de la siguiente manera: "Todos han de observar con fidelidad la mente y propósitos de los fundadores, corroborados por la autoridad eclesiástica competente, acerca de la naturaleza, fin, espíritu y carácter de cada instituto, así como también sus sanas tradiciones, todo lo cual constituye el patrimonio del instituto" (CIC 578).

${ }^{7}$ Cf. A. Romano, "Carisma", en Á. Aparicio RodríGuez - J. M. Canals Casas, Diccionario Teológico de la Vida Consagrada (Claretianas, Madrid 1992) 151.
} 
nuevas comunidades de vida consagrada en la Iglesia ${ }^{8}$. Aparejado a esta expresión se comienza a utilizar el enunciado "carisma de fundación" para indicar el don concedido a los seguidores del fundador para el desarrollo de la comunidad o familia espiritual, de acuerdo al modo original proveniente del patrono; y se acuñan las nociones "carisma del instituto" o "carisma de la fundación" para indicar las cualidades particulares de la nueva familia espiritual en el seno de la Iglesia?.

El camino de aggiornamiento posconciliar impulsó el interés por la figura de los fundadores, e inició una verdadera reflexión teológica. Francis George escribe en 1977 un artículo que titula "Founding «Founderology»: Charism and Hermeneutics" $"$. Podríamos traducir su juego de palabras como "fundando el estudio sobre los fundadores", dando cuenta entonces que -en aquellos años de la recepción del Concilio- comienza la reflexión sobre los fundadores y sus familias religiosas.

Un primer paso fue identificar las características esenciales de los fundadores/as, como pueden ser: experimentarse llamados por Dios a crear una nueva familia de vida evangélica o religiosa; fijar los fines de la misma y trazar la regla de vida en sus líneas fundamentales; dar a sus comunidades reglas o constituciones, aunque no las escriban ellos mismos sino sus colaboradores directos ${ }^{11}$. De estas características brota el valor del retorno a los fundadores, como fuente de la intención originaria del surgimiento del carisma particular de esa familia religiosa.

El magisterio resalta las virtudes y la santidad de los fundadores, Lumen gentium 45 los califica de "ilustres" y Pablo VI reconoce su ejemplo de santidad (ET 11). El carisma de fundador aparece como una riqueza de gracias que posibilitan una gran fecundidad espiritual para dar vida nueva a la Iglesia, como un don que vivifica la vida del fundador y la comunidad que él inicia. El don para empezar una nueva familia carismática incluye también una gran capacidad de inspiración y persuasión, que permite comunicar con profundidad espiritual

8 Cf. M. BALOG, "Charisme fondateur", Studia Canonica 50 (2016) 165-174, en línea: https://doi.org/10.2143/STC.50.1.3136942 (consulta: 01/07/2020).

${ }^{9}$ En la reflexión teológica se utilizaron estos términos con gran variedad de significados, algunos opuestos entre ellos, de acuerdo al autor que los utilizara. A esta dificultad, se suma una utilización excesiva del término carisma, lo que termina haciendo de él un término vago que siempre necesita ser aclarado o desarrollado para indicar a qué realidad se está refiriendo. Cf. G. RocCA, Il carisma del fondatore (Áncora, Milan 1998) 9-78.

${ }^{10}$ F. E. GEORGE, "Founding «Founderology»: Charism and Hermeneutics", Review for Religious 36 (1977) 40-48.

${ }^{11}$ Cf. J. M. Lozano, El fundador y su familia religiosa (Instituto Teológico de Vida Religiosa, Madrid 1978) 15. 
la experiencia recibida, y finalmente forma parte de este carisma "la santidad, eminente en muchos casos, que los distingue" 12 .

Este impulso de redescubrimiento de los fundadores se plasma en un discurso que recupera los aspectos positivos de sus figuras, y se construye buscando resaltar la ejemplaridad de los iniciadores de las familias religiosas. El fundador se percibe no solo como el iniciador de una misión humana, sino como una persona guiada por el Espíritu Santo, desarrollando una tarea que se inscribe dentro de la economía salvífica divina ${ }^{13}$. En esta perspectiva, "el líder carismático es un santo que imitar, fundador que seguir, maestro que escuchar, padre que amar, intercesor que invocar" ${ }^{14}$.

Las décadas de 1970-1980 -impulsadas por la recepción del Conciliofueron el espacio donde surgió un fuerte interés por el carisma de los fundadores, desplegado en investigaciones y estudios generales y específicos de la vida y obra de diversos fundadores en distintas familias religiosas ${ }^{15}$. La motivación de estos trabajos era adquirir una mayor comprensión de la persona y la obra de quien, habiendo iniciado la familia religiosa, quedó olvidado o relegado en la distancia histórica. El objetivo fue rescatar aspectos valiosos verdaderas riquezas- de la experiencia fundacional para iluminar el presente y convertirse en recursos potentes para discernir la misión de los institutos y congregaciones.

Así también lo señala uno de los últimos documentos de la Congregación para los Institutos de Vida Consagrada y Sociedades de Vida Apostólica (CIVCSVA), al describir las primeras décadas del posconcilio como un momento donde el esfuerzo de renovación fue más generoso y creativo que posteriormente, y donde

cada familia religiosa se ha comprometido a fondo a releer e interpretar la "inspiración originaria de los institutos" (PC 2). Esta labor tenía principalmente dos objetivos: custodiar fielmente "la mente y propósitos de los fundadores" (CIC 578) y "reproducir con valor la audacia, la creatividad y la santidad de sus fundadores y fundadoras como respuesta a los signos de los tiempos que surgen en el mundo de hoy (VC 37) ${ }^{16}$.

12 J. M. LozAno, "Fundador", en Á. Aparicio RodrígueZ - J. M. CANALs Casas, Diccionario Teológico de la Vida Consagrada (Claretianas, Madrid 1992) 752.

${ }^{13}$ Cf. G. CiCCHESE, "Ejemplaridad del fundador. Cinco aspectos de la relación con él”, Unidad y Carismas 87 (2013) 21.

${ }_{14}$ M. ZAGO, "Renewing ourselves in the charism of Eugene de Mazenod", citado en G. CICCHESE, "Ejemplaridad del fundador", 21.

15 Cf. F. CIARDI, "Siguen vivos y transmiten vida”, Unidad y Carismas 87 (2013) 4.

${ }^{16}$ CIVCSVA, A vino nuevo, odres nuevos. La vida consagrada desde el Concilio Vaticano II: retos aún abiertos (Claretianas, Buenos Aires 2017) 5. 
Luego de 40 años, el área de estudio ha logrado un relativo desarrollo como un apartado de la reflexión sobre la vida consagrada en la Iglesia. Con el desarrollo de los movimientos eclesiales, las nuevas comunidades y las nuevas formas de vida consagrada alcanzaron un lugar de mayor visibilidad, dada la necesidad de comprender el surgimiento de estas nuevas organizaciones carismáticas nacidas en derredor del Concilio Vaticano II y fuertemente estimuladas durante el pontificado de Juan Pablo II.

Como sabemos, la dimensión carismática de la Iglesia se fue desarrollando mediante el surgimiento de una gran diversidad de institutos religiosos, dando al dinamismo pneumatológico concreción y variedad histórica. Cada familia religiosa que surge es un proyecto existencial derivado del modelo ofrecido por el/la fundador/a, y un don del espíritu para la Iglesia ${ }^{17}$. Una de las características de los años postconciliares fue la difusión de nuevas formas agregativas de fieles, con una gran variedad en sus fisonomías y finalidades, las cuales incluyen los nuevos movimientos eclesiales, las nuevas comunidades y nuevas formas de vida consagrada ${ }^{18}$.

\section{LA TEOlogía DE LOS FUNDADORES APLICADA A LAS NUEVAS FUNDACIONES}

Estudiar los discursos y la percepción sobre los fundadores que existe en el período posconciliar -dentro de las nuevas realidades carismáticas- es complejo, principalmente debido a que "la gran mayoría de la bibliografía dedicada a los movimientos eclesiales consiste en algo así como una hagiografía sobre los fundadores" 19 . Los trabajos sobre los movimientos y sus figuras carismáticas presentan habitualmente una tendencia a describir sus aportes en

${ }^{17}$ Cf. E. VigAno, “Teología y vida religiosa después del Concilio Vaticano II”, Teología y Vida 6 (1985) 255-272, en línea: https:// repositorio.uc.cl/handle/11534/15330 (consulta: 01/07/ 2020).

${ }^{18}$ Cf. J. J. EtXeberría, “Los Movimientos Eclesiales: Fenomenología y Cuestiones Abiertas”, Estudios Eclesiásticos 76 (2019) 5-33, en línea: https://revistas.comillas.edu/index.php/ estudioseclesiasticos/article/view/11160_consulta: 01/07/2020); T. BAHÍLLO RUIZ, "La adhesión a las nuevas formas asociativas eclesiales desde los diversos estados de vida", Estudios Eclesiásticos 81 (2018) 768, en línea: https://revistas.comillas.edu/index.php/ estudioseclesiasticos/article/view/9227 (consulta: 01/07/2020); L. NAVARRO, "Nuevos movimientos eclesiales. Naturaleza de los carismas, cuestiones jurídicas y límites", Ius canonicum 58/116 (2018) 611-634, en línea: https://doi.org/10.15581/016.116.005 (consulta: 01/07/2020); M. Delgado GALINDO, “Asociaciones internacionales de fieles”, Ius canonicum 50 (2010) 10-11, en línea: https://hdl.handle.net/10171/36310 (consulta: 01/07/2020); A. CATTANEO, "Los movimientos eclesiales: cuestiones eclesiológicas y canónicas" Ius canonicum 38/76 (1998) 571-594, en línea: https:// hdl.handle.net/10171/3365 (consulta: 01/07/2020).

${ }^{19}$ M. FAGGIOLI, Historia y evolución de los movimientos católicos de León XIII a Benedicto XVI (PPC, Madrid 2011) 16. 
la evangelización y a defender su puesto en la estructura orgánica en la Iglesia, con un fuerte acento apologético frente a las críticas que reciben.

Un aporte sugerente es el trabajo de Virginia Parodi, quien al realizar una investigación en torno a la persona y al carisma de Josef Kentenich (1885-1968) ofrece una mirada sobre la teología referida a los fundadores y sus carismas en los comienzos del siglo $\mathrm{XXI}^{20}$. Desde una perspectiva histórica y en una apretada síntesis sostiene que

[...] el vocablo fundador se ve sujeto a una evolución que traza un arco extendido desde una función netamente normativa hasta su significación relevante como representante personal del carisma, como centro unificador-comunional de su familia y del desarrollo personal de sus seguidores ${ }^{21}$.

Esta autora distingue cuatro momentos significativos en el desarrollo del concepto teológico de "fundador". En un primer momento los fundadores cumplen una función normativa al dar su fisionomía a un determinado modo de vida comunitaria en la sequela Christi, promulgando reglas y ofreciendo pautas de vida. A partir del siglo VI el vocablo designa a los donantes y patrocinadores que posibilitan centros espirituales en sus territorios. En un tercer momento, con el surgimiento de las ordenes mendicantes y el desarrollo de las congregaciones, se pierde la estabilidad del desarrollo de una familia religiosa vinculada a un lugar y cobra importancia la identificación con el proyecto carismático de los fundadores y la identidad que le imprimen a su familia espiritual ${ }^{22}$. Finalmente, a inicios del siglo XXI, surge un nuevo paradigma: al carisma del fundador para plasmar y configurar una nueva comunidad en la Iglesia concurre la persona misma del fundador como "una realidad vitalmente inseparable del carisma"23.

En las nuevas realidades carismáticas el fundador, en general vivo y presente en el desarrollo de la nueva comunidad, cumple un papel medular como transmisor primario de la experiencia carismática, como referencia única donde confrontar la identidad de la organización con las necesidades de la evangelización, y como factor de unidad de las distintas personas y actividades que componen la nueva familia espiritual.

Este es el acento que ofrecen sobre las figuras fundacionales las nuevas comunidades y movimientos. Dada la pluralidad de formas vocacionales que

\footnotetext{
20 V. PARODI, Beziehung zum Gründer und Treue zum Gründungscharisma in der nachkonziliaren Theologie sowie in geistlichen Neu-Gründungen des 20. Jahrhunderts (Philosophisch-Theologischen Hochschule Vallendar, Vallendar 2007); V. PARODI, El vínculo con el fundador (Florencio Varela, Schoenstatt Nazaret 2011).

${ }^{21} \mathrm{~V}$. PARODI, El vínculo con el fundador, 32.

${ }^{22} \mathrm{~V}$. PARODI, El vínculo con el fundador, 32-35.

${ }^{23}$ V. PARODI, El vínculo con el fundador, 35.
} 
conforman la nueva realidad carismática, el fundador como receptor primario del carisma se convierte en un elemento unitivo de la diversidad de llamados, realidades y servicios dentro de una misma familia espiritual ${ }^{24}$.

Así la entera realidad del movimiento o nueva comunidad se remite al carisma del fundador, que es la referencia espiritual y la mediación privilegiada en la interpretación del carisma de la familia espiritual ${ }^{25}$ : "el fundador pasa a ser símbolo del carácter comunional-relacional del carisma y la relación vital con él, una fuente de compromiso con la comunidad y su misión" ${ }^{26}$.

La teología de los fundadores, desarrollada desde la búsqueda del aggiomamento posconciliar en las congregaciones e institutos más antiguos, es recibida para fundamentar el lugar de liderazgo de los/las distintos fundadores/as o grupos fundacionales. El trabajo de recuperar las figuras fundacionales, de estudiar el contexto histórico, social y político en que obraron, de analizar en profundidad sus biografías y sus escritos para componer un cuadro de su personalidad y su modo de llevar adelante la fundación construye unos criterios y unos fundamentos de una teología de los fundadores. Por otra parte, es necesario destacar que la reflexión teológica desde la vida consagrada se realiza mirando a personalidades del pasado lejano, grandes figuras de la historia eclesial como Benito de Nursia y Escolástica, Francisco y Clara de Asís, Domingo de Guzmán, Ignacio de Loyola, por nombrar algunos.

Ese desarrollo eclesiológico es el sustrato que encuentran las nuevas organizaciones carismáticas para explicar el papel central que ocupa el fundador en ellas. Pero ya no se trata de una figura ubicada en los inicios de la historia de una organización con 1500, 800 o 500 años, sino de una persona viva que concentra múltiples funciones en el seno de una organización naciente motivada por altos ideales. Para complejizar más la cuestión, los fundadores de las nuevas comunidades impulsan y gobiernan una estructura compleja de vocaciones y servicios, y lo hacen en un contexto eclesial que avizora en ellos tanto un peligro como una oportunidad histórica inédita de un desarrollo evangelizador global.

Además, en ocasiones, la doctrina desarrollada anteriormente es tomada por los propios fundadores de las nuevas realidades para describirse a sí mismos en su actividad como iniciadores de nuevas organizaciones carismáticas. La teología de los fundadores se vuelve un marco legitimador de las determinaciones y del modo de decidir de quienes lideran la gestación y el desarrollo de los recientes grupos eclesiales.

\footnotetext{
24 V. PARODI, El vínculo con el fundador, 35.

25 Cf. M. FagGioli, Historia y evolución de los movimientos católicos, 114.

${ }^{26} \mathrm{~V}$. PARODI, El vínculo con el fundador, 36.
} 
La recepción que realizan las nuevas realidades carismáticas de la reflexión sobre los fundadores, para explicar y explicarse cuál es el lugar y el rol del ellos en sus organizaciones, no se realiza en las mismas circunstancias ni con el mismo objetivo.

En principio esta dificultad no es reconocible debido a ciertos conflictos, como la concepción de la obediencia y el servicio de la autoridad del líder carismático. Sin embargo, avanzada la segunda década del siglo XXI, queda en evidencia debido a las escandalosas noticias de los abusos cometidos por un número importante de relevantes figuras carismáticas como fundadores o miembros del grupo fundacional de movimientos y nuevas comunidades.

\section{NECESIDAD DE NUEVAS REFLEXIONES A PARTIR DE LA CRISIS DE LOS ABUSOS}

En el presente se hace imprescindible abrir un nuevo capítulo en la reflexión teológica sobre los fundadores, dada las continuas revelaciones de acusaciones de abusos -sexuales, económicos, de conciencia y espirituales- sobre grandes figuras católicas consideradas maestros espirituales y/o fundadores de nuevas comunidades, tanto sacerdotes como laicos.

A la inicial denuncia de los abusos cometidos por Marcial Maciel Degollado (1920-2008), fundador de la Congregación de los Legionarios de Cristo y del movimiento Regnum Christi ${ }^{27}$, se fueron sucediendo una cadena de denuncias sobre comportamientos corruptos y abiertamente inmorales de otros fundadores o referentes carismáticos de nuevas realidades. En los últimos años, reconocidas figuras en la galaxia de las nuevas comunidades, tanto clérigos como religiosos/as o laicos, son denunciadas y sus víctimas hablan ${ }^{28}$.

En Perú, Luis Figari (1947), fundador y primer superior general del Sodalicio de Vida Cristiana ${ }^{29}$; los fundadores de la Comunidad Misionera de

27 La Congregación de los Legionarios de Cristo ha reconocido los comportamientos gravísimos y objetivamente inmorales de Marcial Maciel Degollado, los cuales incluyeron el abuso de seminaristas menores de edad, actos inmorales con hombres y mujeres adultos, el uso arbitrario de su autoridad y de bienes, el consumo desmesurado de medicamentos adictivos y el haber presentado como propios escritos publicados por terceros. Cf. Congregación de los Legionarios De Cristo, "Mensaje del Capítulo General Extraordinario de los Legionarios de Cristo sobre el camino de renovación que estamos recorriendo, 20 de enero de 2014", 4.

${ }^{28}$ Cf. C. Hoyeau, "Abus dans l'Église, les communautés face à la trahison des fondateurs, $L a$ Croix (22 de octubre de 2019), en línea: https://bit.ly/3glkTlK (consulta: 30/05/20).

${ }^{29}$ El 2 de octubre de 2018, la Signatura Apostólica en el Vaticano rechazó la segunda apelación de Luis Fernando Figari contra las medidas dispuestas por la Congregación para Institutos de Vida Consagrada y Sociedades de Vida Apostólica el 30 de enero de 2017 que le imponían la prohibición de regresar a Perú y el contacto y trato personal directo, de cualquier modo, 
Villaregia (Italia) ${ }^{30}$; un gran número de referentes de nuevas comunidades francesas derivadas de la Renovación Carismática Católica, tales como Gérard Croissant (Éphraïm), fundador de la comunidad de las Bienaventuranzas ${ }^{31}$; Thierry de Roucy (1957), fundador de Puntos-Corazón ${ }^{32}$; Thomas Philippe (1905-1993), co-fundador del Arca con Jean Vanier ${ }^{33}$; Marie-Dominique Philippe (1912-2006), hermano del anterior y fundador de la comunidad de San Juan $^{34}$; Alix Parmentier (†2016), primera superiora de las Hermanas de San

con personas pertenecientes al Sodalicio. Por otra parte, la comunidad del Sodalicio ha señalado que no puede considerar como un referente espiritual a Figari y condena sus abusos. Cf. CONSEJO SuPERIOR DEL SODALICIO, "Medidas tomadas con relación a Luis Fernando Figari, 20 de febrero de 2019”, en línea: https://bit.ly/3cZenz5 (consulta: 30/05/20).

${ }^{30}$ La Comunidad Misionera de Villaregia, fundada en 1981, nació de un encuentro celebrado en Cagliari (1975) entre el Padre Luigi Prandin y Maria Luigia Corona. Debido a graves comportamientos perpetrados por Luigi Prandin en relación a algunas misioneras mayores de edad y el encubrimiento de la co-fundadora, el Pontificio Consejo para los Laicos decretó -en 2012- la remoción del cargo de presidentes de los fundadores, dispuso su dimisión como miembros de la Asociación y los obligó a no residir en el futuro en ninguna casa de la misma. La Asociación tuvo como Comisario pontificio al P. Amedeo Cencini a partir del año 2012. Cf. A. CEnCINI, Nota ufficiale di P. Amedeo Cencini sul commissariamento della CMV, junio de 2012, en linea: https://bit.ly/2Bk01KN (consulta: 20/03/2020).

${ }^{31} \mathrm{La}$ comunidad de las Bienaventuranzas reconoció las conductas improcedentes de miembros en posiciones importantes. Tanto el fundador Gérard Croissant -Éphraïm-, como Philippe Madre -cuñado de Éphraïm-, quien lo sucedió como Moderador General, y Pierre-Étienne Albert, cercano al fundador, fueron hallados responsables de diversos delitos de índole sexual, incluso con menores. Tanto Croissant como Madre fueron relevados de su ministerio diaconal. Cf. C. LESEGRETAIN, "Les Béatitudes reconnaissent la gravité des délits de certains de leurs anciens membres, La Croix (16 de noviembre de 2011), en línea: https://bit.ly/36yaUoz (consulta: 30/05/20).

32 En 1990, Thierry de Roucy, entonces Superior General de la Congregación de los Siervos de Jesús y María, creó la obra Points-Coeur (Puntos Corazón), que envía voluntarios para vivir en grupos de cuatro o cinco en los lugares más pobres del planeta. Thierry de Roucy se reconoció culpable y fue condenado en julio de 2011 por abuso de poder, abuso sexual y absolución del cómplice. Monseñor Dominique Rey (obispo de la diócesis de Fréjus-Toulon) lo suspende a divinis, en febrero de 2016, por desobediencia al no cumplir con la solicitud de no mantener vínculos con la obra Points-Coeur. En 2018 fue expulsado del estado clerical. Cf. D. LAURENCE - A.-L. FILHOL, "Après la réduction à l'état laïc de son fondateur, retour sur l'affaire PointsCœur, La Vie (28 de junio de 2018), en línea : https://bit.ly/3d0d177 (consulta : 30/05/20).

33 En 2014, la comunidad de El Arca tomó conocimiento de múltiples acusaciones contra el presbítero Thomas Philippe por abuso sexual grave contra varias mujeres. A pedido del gobierno de la comunidad se lanzó inmediatamente una investigación canónica; en $2019 \mathrm{El}$ Arca Internacional encargó una investigación exhaustiva e independiente, diseñada para comprender mejor su historia y errores, buscando continuar desarrollando políticas y prácticas para prevenir y manejar el abuso. Cf. FEDERATION INTERNATIONALE DeS COMMUNAUTES DE L'ARCHe, "Press release after the Arte Documentary - March 2019", en línea: https://bit.ly/3gfOsoG (consulta: 30/05/20).

${ }^{34} \mathrm{La}$ comunidad de San Juan posee tres congregaciones: los Hermanos de San Juan, las Hermanas Contemplativas (fundada en 1982) y las Hermanas Apostólicas (creada en 1984). 
Juan $^{35}$; Mansour Labaky (1940), fundador del movimiento espiritual maronita «Lo Tedhal-No tenga miedo» ${ }^{36}$; Bernard Peyrous (1947), reconocido miembro de la comunidad del Emmanuel ${ }^{37}$; André-Marie Van Der Borght (1925-2004) ${ }^{38}$ y Georges Finet (1898-1990) ${ }^{39}$, personalidades relevantes en los Foyers de

Desde el 2013, el prior general de los Hermanos de San Juan había dado a conocer -por propia iniciativa- que el fundador, el padre Marie-Dominique Philippe, había cometido abusos contra mujeres adultas -algunas religiosas- y abusos de autoridad. En un Capítulo General, concluido en noviembre de 2019, la organización carismática ha decidido distanciarse de su fundador deshonrado y "refundarse" sin ninguna referencia a él. Cf. Hermanos DE SAN JuAN, "Comunicado, 07 de febrero de 2019", en línea: https://bit.ly/2TAKrkT (consulta: 30/05/20); C. HOYEAU, "Brothers of St. John distance themselves from disgraced founder Congregation to be re-founded without reference to the priest who abused several women, La Croix (06 de noviembre de 2019), en línea: https://bit.ly/3ecW7Cm (consulta: 30/05/20).

35 La hermana Alix Parmentier, superiora desde 1982, fue despedida en 2009 por decreto del cardenal Barbarin, luego de acusaciones que apuntaban a hechos serios. La hermana Alix no acepta estas decisiones y se genera una fuerte división. El comisionado pontificio pidió a cuatro hermanas (incluida la hermana Alix) que ya no influyeran en el resto de la comunidad, sin que esto pudiera concretarse. En el año 2013 reciben como Visitador Apostólico al cardenal João Braz de Aviz, se resuelven algunas cuestiones y por decisión del Papa Francisco las cuatro hermanas son excluidas de la vida religiosa. El Papa Francisco realiza declaraciones en el año 2019, que parecen referirse a estas situaciones, y son aclaradas por el director de la sala de prensa del Vaticano precisando que el Santo Padre ha utilizado el término de "esclavitud" para significar "manipulación" como un abuso de poder que puede traducirse en situaciones de abusos sexuales. Véanse los textos citados en la nota anterior.

36 Mansour Labaky fue condenado por la Congregación para la Doctrina de Fe por delitos sexuales contra menores de 15 años, por decreto del 23 de abril de 2012 y confirmado el 19 de junio de 2013. Conocido por su acción a favor de las víctimas y los huérfanos de la guerra del Líbano, fue procesado por la justicia francesa por pedofilia. Considerado en su país como un héroe nacional, el sacerdote goza de un poderoso apoyo, comenzando con la Iglesia Maronita. Cf. C. HoYEAU, "Pédophilie, le P. Labaky visé par un mandat d'arrêt international, La Croix (26 de abril de 2016), en línea: https://bit.ly/2ZxzvbF (consulta: 30/05/20).

${ }^{37}$ Bernard Peyrous, especialista en historia de la espiritualidad y teología espiritual, fue rector de los santuarios de Paray-le-Monial y postulador de la causa de beatificación de Marta Robin. Es una figura importante en la comunidad del Emmanuel. En 2017 fue destituido de su cargo por gestos seriamente inapropiados de su parte frente a una mujer adulta. El sacerdote admitió los hechos, la víctima se negó a presentar una denuncia y no se hizo ningún informe a la justicia. Cf. M. LE PRIOL, "Imbroglio autour du transfert d'un prêtre accusé de «gestes gravement inappropriés», La Croix (26 de marzo de 2019), en línea: https:// bit.ly/ 3bWDW2d (consulta: 30/05/20).

${ }^{38}$ Los Foyers de Charité revelaron en 2018 la existencia de varios testimonios creíbles de mujeres que denuncian gestos y comportamientos inapropiados por parte del padre AndréMarie van der Borght, quién fuera una figura carismática en el surgimiento de esta red de comunidades. Cf. M. NDIOnE, “ Message aux membres et aux amis des Foyers de Charité au sujet du père André-Marie van der Borght (2018)", en línea: https://bit.ly/3gcrmiG (consulta: 30/05/20).

${ }^{39}$ Las investigaciones informadas recientemente a la Comisión Permanente de la Conferencia de Obispos de Francia señalan que Georges Finet (1898-1990), quién había acompañado a 
Charité; Jacques Marin (1929-2019), vinculado al tiempo fundacional y desarrollo de la comunidad Verbe de $\mathrm{Vie}^{40}$. A fines de 2019, se realizan acusaciones de control psicológico y espiritual durante el tiempo fundacional contra el hermano Pierre-Marie Delfieux (1934-2013), fundador de las Comunidades Monásticas de Jerusalén ${ }^{41}$.

Finalmente, comenzando el año 2020, se conocieron las conclusiones de una investigación confiada por la federación El Arca a un organismo externo e independiente. Durante esa pesquisa se recibieron testimonios creíbles que indican comportamientos sexuales incorrectos en el marco del acompañamiento espiritual por parte de Jean Vanier (1928-2019) ${ }^{42}$. La relevancia de la figura de Jean Vanier como referente de los movimientos eclesiales es superlativa, y es uno de los selectos fundadores, sentado en 1998 en la Plaza San Pedro, celebrando la primavera de la Iglesia anunciada por Juan Pablo II.

El elenco realizado permite describir el impacto de las denuncias de abusos sobre las nuevas realidades carismáticas y especialmente sobre fundadores, líderes carismáticos o figuras notables en la generación fundacional. No se trata de un fenómeno irrelevante, sino de una verdadera conmoción que, experimentada por las nuevas comunidades dentro de la convulsión generada por la crisis de los abusos, moviliza a una seria y profunda reflexión para poder reconocer los componentes que favorecieron estas conductas deshonestas o impidieron su develamiento y castigo ${ }^{43}$.

Marta Robin en la fundación de los Foyers de Charité, fue responsable de conductas seriamente desviadas durante las confesiones de niñas jóvenes, en su mayoría de 10 a 14 años, en el período de 1945 a 1983. Cf. Comision Permanente de la Conferencia de OBispos DE FrAnCia, "Les Foyers de Charité révèlent les agissements du Père Georges Finet", (07 de mayo de 2020), en línea: https://bit.ly/2WWfRUZ (consulta: 30/05/20); S. LEBRUN, "Abus sexuels, emprise: révélations des Foyers de charité sur leur fondateur, (07 de mayo de 2020), La vie (2020), en línea: https://bit.ly/3d5XPpa (consulta: 30/05/20).

40 Jacques Marin, tuvo una gran influencia dentro de la Renovación Carismática en Francia, vinculado a la fundación de la comunidad Verbe de Vie y a su desarrollo hasta el año 2013, desarrollaba su ministerio como predicador de la Renovación Carismática, de la comunidad de las Bienaventuranzas y del Emmanuel. Fue hallado culpable de abusos múltiples cometidos en el contexto de la confesión. Cf. C. HOYEAU, "Décès de Jacques Marin, prêtre aux multiples victimes, La Croix (14 de octubre de 2019), en línea: https://bit.ly/3gnAmlo (consulta: 30 de mayo 2020).

41 A. MARdon, Quand l'Église détruit (L'Harmattan, París 2019); J.-C. CALMON - R. BulZAGA, “Communiqué de presse, 10 de décembre de 2019”, en línea: https://bit.ly/3gj91PU (consulta: 30/05/20).

42 L'ARChe InTERnATIONAL, “Summary Report from L'Arche International, February 22, 2020”, en línea: https://bit.ly/36pvwzp (consulta: 30/05/20).

43 Cf. H. Zollner, "Las heridas espirituales causadas por los abusos sexuales", La Civiltà Cattolica Iberoamérica 12 (2018) 45. 
"Existen «otros» Marcial Maciel”, señaló explícitamente el cardenal João Braz de Aviz, indicando así que hay más de un fundador de congregaciones, institutos religiosos y movimientos que no vivieron o no viven de acuerdo a la propuesta que han ofrecido a sus seguidores ${ }^{44}$.

La confrontación con los múltiples casos de fundadores o líderes carismáticos señalados, evidentemente, debe interrogar nuestra comprensión de los fundadores; genera, además, un verdadero cambio de paradigmas en la eclesiología de los carismas. Ya no es posible afirmar que el caso de Marcial Maciel "es único en la historia de la Iglesia"45, o pensar que se trata de otras dificultades y conflictos vividos entre el fundador y la comunidad fundada como ya han existido en la historia ${ }^{46}$.

\section{LÍNEAS DE DESARROLLO DE LA REFLEXIÓN ECLESIOLÓGICA SOBRE EL LIDERAZGO DE LOS FUNDADORES EN LA DIMENSIÓN CARISMÁTICA DE LA IGLESIA}

La comprensión del momento eclesial muestra la necesidad de un abordaje teológico de la crisis de los abusos sexuales, y no una mera investigación legal enfocada en la criminalidad de los actos. Si se simplifica la cuestión, y se abandona solamente al aspecto legal, no será posible visibilizar las raíces causales de la crisis de los abusos en la Iglesia y también en las organizaciones carismáticas ${ }^{47}$.

Si bien no todos los grupos afrontan problemas tan graves y escandalosos, muchos de ellos comparten las complejas cuestiones que permitieron la corrupción de las dinámicas de poder en las comunidades eclesiales. La introducción de la nueva sensibilidad teológica que identifica el problema del abuso sexual con el abuso de poder no puede soslayarse si se desea desarrollar estructuras sanas con perspectivas de futuro ${ }^{48}$.

Lo sucedido muestra la necesidad de analizar el aspecto institucional, específicamente las disfunciones sistémicas en la Iglesia y, también, en las

\footnotetext{
44 A. Beltramo Álvarez, "La Santa Sede reconoce: existen «otros» Maciel, 31 de enero de 2014”, La Stampa (2014), en línea: https:/ / bit.ly/3cVoTqV (consulta: 30/05/20).

45 "Ciertamente ha habido fundadores, aunque pocos, que por una $\mathrm{u}$ otra causa no han continuado con la construcción de su familia espiritual o que, humanamente, hablando, se podría alegar que han sido infieles al carisma recibido. Pero nunca se había dado un caso de tal envergadura", continúa señalando la autora. Cf. V. PARODI, El vínculo con el fundador, 48.

46 Cf. F. CIARDI, "Siguen vivos y transmiten vida", 4.

47 Cf. M. Faggioli, "The Catholic Sexual Abuse Crisis as a Theological Crisis: Emerging Issues", 573.

${ }^{48}$ Cf. M. Faggioli, "The Catholic Sexual Abuse Crisis as a Theological Crisis: Emerging Issues", 573.
} 
organizaciones carismáticas ${ }^{49}$. La tarea supone cuestionar las ideas teológicas a la base de los desajustes estructurales que han dejado en evidencia las denuncias sobre personalidades altamente relevantes. Más todavía cuando los análisis realizados confluyen con propuestas de reforma ya existentes en la Iglesia ${ }^{50}$, y lo mismo sucede a nivel de las organizaciones carismáticas donde las observaciones esbozadas coinciden con planteos de referentes como la CIVCSVA $^{51}$ o el reconocido experto de la vida religiosa Amedeo Cencini ${ }^{52}$.

Las investigaciones sobre los abusos llevadas adelante desde la Iglesia, las congregaciones religiosas, los Estados y los organismos independientes ya conforman un abultado cuerpo científico que impiden mirar hacia otro lado, y obligan a abrir una discusión sobre las personalidades carismáticas y sus comunidades en la Iglesia Católica, dadas las condiciones particulares favorables al abuso creado por algunos modos de configurarse de las nuevas realidades eclesiales ${ }^{53}$.

Hasta ahora los nuevos movimientos y comunidades eclesiales no formaron parte de la conversación sobre la crisis mundial de abuso y no se han interesado por la reforma institucional, cuestión inevitable que dejan planteados los análisis sobre la crisis de los abusos ${ }^{54}$.

Una de las cuestiones a examinar, al introducir las nuevas comunidades en esta conversión a partir de la crisis de los abusos, es la acumulación de poder que existe en los líderes carismáticos en estas nuevas organizaciones, en algunos de ellos unida a la potestad sacerdotal. Así como en la reflexión sobre los abusos se comienza a investigar sobre el modo en que es concebido el sacerdote, también debe indagarse la manera en que es percibido el fundador como figura carismática en las nuevas comunidades.

En muchas partes del mundo los sacerdotes aún son vistos como irreprensibles mensajeros de Dios a los que está reservada una fuerza, autoridad y capacidad

${ }^{49}$ Cf. C. SCHICKENDANTZ, "Fracaso institucional de un modelo teológico-cultural de Iglesia. Factores sistémicos en la crisis de los abusos", 9-40.

${ }^{50}$ Cf. C. SCHICKENDANTZ, "Fracaso institucional de un modelo teológico-cultural de Iglesia", 12.

${ }^{51}$ Cf. CIVCSVA, A vino nuevo, odres nuevos.

52 A. CENCINI, "El arte del acompañamiento en la formación. Respetar la tierra sagrada del otro: proximidad y libertad", en CONSEJO PONTIFICIO PARA LOS LAICOS, "III Congreso Mundial de los Movimientos Eclesiales y las Nuevas Comunidades", 20 al 22 de noviembre de 2014, Roma, en línea: https://goo.gl/EQsnHV (consulta: 13/05/20); A. CENCINI, ¿Ha cambiado algo en la Iglesia después de los escándalos sexuales? Análisis y propuestas para la formación (Sígueme, Salamanca 2016).

${ }^{53}$ M. FAgGioli, "The Catholic Sexual Abuse Crisis as a Theological Crisis: Emerging Issues", 586.

${ }^{54}$ M. FAgGioli, "The Catholic Sexual Abuse Crisis as a Theological Crisis: Emerging Issues”, 586. 
de gobierno particulares derivadas más o menos directamente de Dios. Una imagen tal del sacerdote puede llevar a los fieles a una idealización inviolable que hace difícil, casi imposible, criticar su figura o tan solo imaginar que él pueda cometer algún acto malo ${ }^{55}$.

Las investigaciones independientes señalan que la idealización del sacerdocio y la identificación virtual de la santidad y la gracia de la iglesia con el estado clerical y con el sacerdote mismo, fomentó la cultura de una "obediencia deferente", donde la persona condesciende al dictamen ajeno, sin querer sostener el suyo ${ }^{56}$.

El abuso de poder del fundador es análogo al abuso del poder del clérigo, pues ambos son figuras pneumáticas, carismáticas, vocacionales. Las mismas prácticas de deferencia, beneplácito y reverencia inmerecida inherentes a la doctrina católica del sacerdocio se dan en la teología sobre los fundadores como figuras carismáticas ${ }^{57}$.

La tendencia a realzar su figura y la obra del Espíritu Santo en él se desarrolló respondiendo a la recepción de las exhortaciones del Vaticano II, mirando a figuras carismáticas distanciadas históricamente por cientos de años y con el objetivo de rescatar elementos que se habían perdido varias generaciones atrás. Posteriormente, esa misma reflexión teológica sobre los fundadores y su carisma se aplicó acríticamente sobre las figuras de las nuevas comunidades, suponiendo que el desarrollo de la obra fundada era suficiente indicativo de que este fundador sería un modelo de perfección evangélica como aquellos fundadores redescubiertos en el posconcilio.

La utilización de esta reflexión teológica -sin observar el contexto y ahistóricamente- coadyuvó a construir una idealización carismática del líder comunitario. Otros factores se acumularon para conformar una situación proclive al abuso: la creación de relaciones de extrema dependencia fundadordiscípulos fundamentada en una falsa concepción de la obediencia, la propuesta de una rigurosa conducta religiosa que prohibía y penaba toda forma de crítica, la falta de observancia de normas fundamentales de la tradición espiritual (separación entre el fuero interno y el fuero externo), hasta llegar a los abusos en el sacramento de la confesión ${ }^{58}$.

\footnotetext{
${ }^{55}$ H. ZOLLNER, "Las heridas espirituales causadas por los abusos sexuales", 55.

56 Cf. R. LENNAN, "Beyond Scandal and Shame? Ecclesiology and the Longing for a Transformed Church", Theological Studies 80 (2019) 603, en línea: https://doi.org/10.1177/ 0040563919856370 (consulta: 01/07/2020); C. SCHICKENDANTZ, "Fracaso institucional de un modelo teológico-cultural de Iglesia. Factores sistémicos en la crisis de los abusos", 27.

${ }^{57}$ Cf. M. Faggioli, "The Catholic Sexual Abuse Crisis as a Theological Crisis: Emerging Issues", 581.

${ }^{58}$ Cf. H. ZolLner, “Las heridas espirituales causadas por los abusos sexuales”, 58.
} 
El fundamento espiritual que se daba a la autoridad y al poder absoluto del líder carismático encuentra algunas razones, que luego son extendidas a otras áreas, en la concepción del santo fundador de la reflexión teológica posconciliar. El interés por la vida de los fundadores ofreció un discurso propicio que permitió explicar el lugar carismático del líder. Luego con una concepción de autoridad absoluta ya construida, el resto se logró evitando el crecimiento de los órganos de control y balance del poder, impidiendo el desarrollo de estructuras de gobierno claras, permitiendo límites jerárquicos ambiguos y fomentado mentalidades de "trinchera" o cluster que aíslan y desacreditan una comunicación abierta. ${ }^{59}$

La necesidad de legitimar la autoridad del fundador, tanto en la definición de la identidad carismática de la nueva comunidad como en la organización institucional y funcional, encontró en la doctrina desarrollada por las congregaciones tradicionales un discurso potente para sustentar la figura altamente idealizada del líder. También permitió justificar la validez de las decisiones tomadas unilateralmente en la capacitación recibida por el Espíritu Santo a través del "carisma de fundador" recibido.

La experiencia de la crisis de los abusos enseña que, tanto la potestad del fundador -como la del sacerdote-, no pueden convertirse en autoridades privadas -cerradas sobre sí mismas- aun cuando sean justificadas espiritualmente por medio del recurso al carisma o a la gracia recibida de estado o de función. Las contemporáneas reflexiones sobre la autoridad en las organizaciones de la dimensión carismática han asumido la necesidad de señalar el lugar erróneo conferido al fundador como único intérprete de un carisma, o considerar equivocadamente que la autoridad pneumática o gracia carismática habilita a sustraerse de las normas del derecho universal de la Iglesia $^{60}$.

La diferencia entre las reflexiones del cercano posconcilio sobre los fundadores y la apropiación de estas ideas en las nuevas realidades carismáticas son dos: la temporalidad y la motivación inicial.

Primero, es necesario considerar el tiempo transcurrido entre la fundación y la reflexión sobre ella. Las primeras reflexiones posconciliares desarrollaron la teología de los fundadores mirando a un pasado distante o muy lejano cronológicamente, donde en todo caso los fundadores y fundadoras y aún la generación fundacional ya habían fallecido. La tarea fue de investigación histórica y de interpretación de los datos rescatados para construir una visión de los hechos fundacionales y del rol del fundador.

\footnotetext{
${ }^{59}$ Cf. H. ZoLlner, "Las heridas espirituales causadas por los abusos sexuales", 58.

${ }^{60}$ Cf. CIVCSVA, A vino nuevo, odres nuevos, 20.
} 
En el caso del desarrollo de la cuestión por parte de las nuevas comunidades se trata de la utilización de la doctrina ya acuñada para analizar un fenómeno presente -contemporáneo- donde las personalidades carismáticas viven o han fallecido recientemente, o aún más, los mismos fundadores son quienes interpretan este pensamiento teológico-histórico para leer su propia experiencia como iniciadores de un nuevo carisma en la Iglesia.

Segundo, hay que señalar cuál es la motivación que da origen al estudio de los fundadores. Las congregaciones e institutos tradicionales se volcaron a esta tarea respondiendo a una propuesta de los padres conciliares del Vaticano II en un claro movimiento de recepción de sus invitaciones. El impulso es exógeno, genera una corriente de renovación y de revisión de la misión de las organizaciones.

En el caso de los nuevos grupos eclesiales las motivaciones son endógenas y apologéticas. Por una parte, tanto frente a los propios miembros de las nuevas realidades como frente a la comunidad eclesial, fue necesario explicar la autoridad del fundador. Por otra, dadas las críticas recibidas desde diversos sectores eclesiales (por ejemplo, comportarse como "Iglesias paralelas") ${ }^{61}$, fue preciso legitimar la autonomía de las figuras fundacionales.

Esta autoridad absoluta era necesaria para determinar la identidad y la misión de la nueva realidad, justificar la aglomeración del poder de decisión del fundador sobre el funcionamiento institucional y darle un valor de revelación carismática a las iniciativas evangelizadoras y al modo de llevarlas adelante. El impulso es mayormente endógeno, y de una defensa abroquelada que contribuyó a construir mentalidades colectivas cerradas sobre sí mismas.

Un nuevo desarrollo, en la reflexión eclesiológica sobre el lugar y el aporte de los fundadores en la gestación y desarrollo de nuevas organizaciones en la Iglesia, podría atender a diferenciar los análisis según el criterio de la distancia temporal. Así sería posible adoptar ciertos puntos de vista hermenéuticos para estudiar fundaciones con un innegable recorrido histórico, y otros para analizar el surgimiento de organizaciones recientes, donde algunas de las categorías pueden ser utilizadas para ambas situaciones. Evidentemente, en ambas perspectivas será necesario un modelo interdisciplinar incorporando los

${ }^{61}$ La visión positiva de Juan Pablo II sobre el aporte de los nuevos movimientos a la evangelización en las sociedades secularizadas no era compartida por muchos. Durante el Sínodo de los Obispos del año 1987, que analizó el lugar del laicado en la Iglesia, los cardenales Martini, Lorscheider y Tomásek hablaron de los movimientos como "Iglesias paralelas". Cf. M. FAGGIOLI, Historia y evolución de los movimientos católicos, 136. 
desarrollos actuales de otras disciplinas como la teoría de las organizaciones, la psicología organizacional, etc. ${ }^{62}$

El estudio histórico y la interpretación de los datos recabados serán aportes importantes para seguir estudiando los procesos de fundación y los roles de las figuras fundacionales. Si bien se señalan experiencias conflictivas a lo largo de la historia, no se describen profundamente ni parecen indicar la existencia de abusos tan graves como los reseñados en este artículo ${ }^{63}$. Una profunda revisión histórica que investigue el devenir de las congregaciones e institutos que no lograron atravesar la etapa fundacional, no consiguieron proseguir en la etapa post-fundacional o encontraron serios problemas al revisar la historia de su origen, podrían dar pautas para pensar los caminos de las nuevas fundaciones.

La investigación sobre datos más actuales también ofrecería información relevante para analizar el pasado reciente, pensar el presente y proyectar el futuro con información objetiva e interpretaciones críticas. La posibilidad de contar con información actualizada e interpretada sobre los procesos de las 831 nuevas fundaciones relevadas por G. Rocca en el año 2010 -donde ya se señalaban la existencia de comunidades con dificultades (Legionarios, Comunidad de San Juan), la existencia de 70 de estas comunidades que recibían la visita o la ayuda de alguna forma de Comisario y la realización de 15 investigaciones sobre los fundadores- sería un valioso insumo en una reflexión eclesiológica para construir aportes a partir de la experiencia de las fundaciones más recientes ${ }^{64}$.

Otro aspecto a recuperar, actualizándolo, es una hermenéutica para leer e interpretar, críticamente, la sensibilidad del fundador y el espíritu con que fue recibida su inspiración por la comunidad fundacional de la realidad carismática. En la teología del fundador posconciliar existía una mirada crítica e interpretativa de su figura en su contexto histórico, aun tratándose de santos canonizados y grandes congregaciones, se buscaba comprender el horizonte de significado y la acción del fundador como hombre de su época, reconociendo

62 En esta perspectiva de integración interdisciplinar para analizar las dinámicas organizacionales, son interesantes los análisis realizados mediante simulaciones numéricas sobre los comportamientos de fundadores, miembros conformistas y no conformistas en las organizaciones carismáticas. Cf. A. ANTOCI - L. BRUnI - P. RusSu - A. SMERILLI, "The founder's curse: the stronger the founder, the weaker the organization", Communications in Nonlinear Science and Numerical Simulation 84 (2020), en línea: https://doi.org/10.1016/j.cnsns. 2020.105191 (consulta: 01/07/2020).

${ }^{63}$ Fabio Ciardi señala algunos ejemplos de circunstancias complejas en procesos fundacionales para el caso de Margaret Anna Cusack, Clelia Merloni, Barbara Micarelli o los conflictos entre el beato Santiago Alberione y las primeras superioras de tres de los institutos fundados por él: las Hijas de San Pablo, las Pastoras, y las Apostólicas. Cf. F. CiARDI, "Siguen vivos y transmiten vida", 4-5.

${ }^{64}$ G. RoccA, Primo censimento delle nuove comunità (Urbaniana University Press, Roma 2010). 
aspectos negativos o limitados de su personalidad o del modo de desarrollar la fundación que podían explicarse históricamente, pero actualmente no son aceptables (por ejemplo, concepciones autoritarias del compromiso religioso de obediencia) ${ }^{65}$.

Uno de los límites de las experiencias fundacionales, más recientes, es la pérdida o la desvalorización del sentido crítico y la concentración del ejercicio del discernimiento en la persona del líder carismático. Una reflexión eclesiológica, sobre los procesos fundacionales, deberá integrar la existencia de instancias de revisión crítica y actualización de la inspiración fundacional y valorar las estructuras institucionales que permiten el desarrollo de estas acciones en el seno de cualquier organización eclesial.

Otra de las temáticas que surgen cada vez que se devela una nueva denuncia sobre el comportamiento corrupto o abiertamente inmoral de una figura relevante de las organizaciones carismáticas, es la pregunta por la relación entre el carisma del fundador y el carisma que ha dado lugar al desarrollo de la organización en la Iglesia, en algunos casos de grandes obras con numerosos miembros de diversas vocaciones. La distinción, aparentemente no tan simple entre el don que representa el carisma de ese nuevo grupo para la Iglesia y el fundador de esa organización, no resuelve la cuestión planteada.

Ante los primeros escándalos, se señaló la excepcionalidad de los hechos sin poner en cuestión la teología subyacente en la relación gracia o santidad del fundador y don del carisma iniciado. Enfrentados actualmente a múltiples revelaciones, que ponen a prueba la relación entre carisma del fundador y carisma de la fundación, se abre la necesidad de profundizar en la teología de los carismas, pero no solo desde una perspectiva de la gracia y la espiritualidad, sino también incorporando aquellos elementos que ofrecen otras disciplinas. Quizá una sana relativización de la figura del fundador -para pasar a estudiar a la comunidad reunida en torno a él, como conjunto imprescindible para el desarrollo de la organización- abra algunos aportes valiosos a esta discusión.

Frente a quienes analizan el surgimiento de nuevas organizaciones y lo explican solo desde perspectivas espirituales, se presenta atrayente la posibilidad de confrontar los aportes de quienes investigan el complejo fenómeno del liderazgo religioso y los mecanismos de transferencia en la relación líder-seguidor ${ }^{66}$. El estudio del liderazgo espiritual ha emergido como

${ }^{65}$ Cf. F. E. GEORGE, "Founding «Founderology»: Charism and Hermeneutics", 43.

${ }^{66}$ S. A. KENEL, "The Birth and Death of Religious Leaders", Journal of Religion and Health 26 (1987), en línea: https://doi.org/10.1007/BF01533679 (consulta: 01/07/2020). 
un nuevo enfoque y paradigma ${ }^{67}$, que posibilita examinar tanto el comportamiento de las figuras carismáticas como de sus seguidores, y proponer estrategias para el desarrollo de estructuras y vínculos sanos en el seno de estas organizaciones ${ }^{68}$.

Otras perspectivas para analizar el comportamiento de las instituciones carismáticas provienen de los estudios realizados desde la sociología de la religión sobre los nuevos movimientos religiosos y las mega-iglesias pentecostales, donde los conflictos por el liderazgo y la sucesión de los iniciadores de estas realidades son áreas de estudio amplias y prometedoras ${ }^{69}$.

\section{CONCLUSIONES}

La galaxia diversa de nuevas realidades carismáticas es uno de los fenómenos de la Iglesia Católica global desarrollado en los años posconciliares. Recién comenzamos a comprender este fenómeno, que no es homogéneo tanto a nivel de las grandes diferencias entre los distintos grupos como al interior de las mismas comunidades, que -a su vez- presentan contrastes ad intra por motivos geográficos y culturales de los países donde se desarrollan (por ejemplo, desde el punto de vista de las relaciones entre los líderes de estos movimientos y el mundo político $)^{70}$.

El surgimiento y desarrollo de los movimientos presentó -y sigue presentando- desafíos eclesiológicos que aún deben dilucidarse, tanto a nivel de las relaciones con la Iglesia universal y local como a nivel interno en las relaciones autoridad-carisma dentro de estas organizaciones.

La revelación de los escándalos obliga a continuar desarrollando estas reflexiones. La gravedad de los acontecimientos denunciados presenta la posibilidad de romper con las dificultades para estudiar la realidad eclesiológica de las nuevas realidades carismáticas. Los obstáculos para esta reflexión se

${ }^{67}$ Cf. J. OH - J. WANG, "Spiritual leadership: current status and Agenda for future research and practice", Journal of Management, Spirituality \& Religion (2020), en línea: https://doi.org/ 10.1080/14766086.2020.1728568 (consulta: 01/07/2020).

${ }^{68}$ Cf. S. Krishnakumar - J. D. Houghton - C. P. NeCK - C. N. Ellison, "The «good» and the «bad» of spiritual leadership”, Journal of Management, Spirituality \& Religion 12:1 (2015) 1737, en línea: https://doi.org/10.1080/14766086.2014.886518 (consulta: 01/07/2020).

${ }^{69}$ Cf. P. Bunton, "Reflexivity in practical theology: reflections from studies of founders' succession in Christian organizations", Practical Theology 12:1 (2019) 81-96, en línea: https://doi.org/10.1080/1756073X.2019.1575039 (consulta: 01/07/2020); KATIE E. Corcoran - K. E., Wellman JR. - J. K, “«People Forget He’s Human»: Charismatic Leadership in Institutionalized Religion”, Sociology of Religion: A Quarterly Review 77:4 (2016) 309-332, en línea: https://doi:10.1093/socrel/srw049 (consulta: 01/07/2020).

${ }^{70}$ Cf. M. Faggioli - D. S. Yocum, Sorting Out Catholicism: A Brief History of the New Ecclesial Movements, 197. 
deben, por una parte, a la reticencia de los miembros de las nuevas fundaciones a dejar el discurso meramente entusiasta que reprime asumir los problemas existentes y presentar una mirada crítica; por otra parte, al discurso acusador que analiza los movimientos en términos de conspiración político-eclesial y que ve en ellos sólo comportamientos sectarios ${ }^{71}$.

Así como la historia de los nuevos movimientos católicos está íntimamente entrelazada con la historia del papado moderno y la Iglesia Católica contemporánea, también está unida al escándalo producido por las denuncias de abusos sexuales y los inevitables cambios institucionales que devendrán.

Se abre en este momento -y por circunstancias dramáticas- la posibilidad de una nueva reflexión sobre el lugar de los fundadores en el surgimiento de una nueva familia religiosa en la Iglesia. Y como consecuencia, para pensar la eclesiología de las organizaciones religiosas dando un lugar más apropiado a las figuras carismáticas fundacionales hacia dentro de la comunidad, y en el marco de la Iglesia local y universal.

Evidentemente, la crisis de los abusos obliga a reflexionar sobre los estilos de liderazgo en la Iglesia y en las organizaciones carismáticas. Asumir en la reflexión teológica el nuevo paradigma de abuso sexual, que "si bien apunta al abuso sexual cometido a menores de edad, busca no reducirse a la edad, sino a las asimetrías de poder posibles que hacen que una interacción sea abusiva y vulneratoria" 72 supone una verdadera transformación de la Iglesia y, por tanto, de la dimensión carismática en ella.

71 Cf. M. Faggioli - D. S. Yocum, Sorting Out Catholicism: A Brief History of the New Ecclesial Movements, 198.

${ }^{72}$ J. A. Murillo, "Abuso sexual, de conciencia y de poder: hacia una nueva definición", Estudios Eclesiásticos 95 (2020) 436, en línea: https://revistas.comillas.edu/index.php/ estudioseclesiasticos/article/view/12180 (consulta: 01/07/2020). 